\title{
Erratum: "Comparative Analysis of Immune Responses in Colorado Potato Beetle Larvae during Development of Mycoses Caused by Metarhizium robertsii, M. brunneum, and M. pemphigi" \\ [Journal of Evolutionary Biochemistry and Physiology, 2016, Vol. 52, No. 3, pp. 252-260]
}

M. V. Tyurin ${ }^{a}$, V. Yu. Kryukov ${ }^{a *}$, O. N. Yaroslavtseva ${ }^{a}$, E. A. Elisafenko ${ }^{b}$, I. M. Dubovskiy ${ }^{a}$, and V. V. Glupov ${ }^{a}$

a Institute of Systematics and Ecology of Animals, Siberian Branch of the Russian Academy of Sciences

${ }^{b}$ Institute of Cytology and Genetics, Siberian Branch of the Russian Academy of Sciences, Novosibirsk, Russia

*e-mail: krukoff@mail.ru

Received December 10, 2014

DOI: $10.1134 / \mathrm{S} 1234567816050165$

On page 258, right column, the final line of the ACKNOWLEDGMENTS should read: The study was financially supported by the Russian Scientific Foundation (project no. 15-14-10014). 